\title{
Ichthyoses-A Clinical and Pathological Spectrum from Heterogeneous Cornification Disorders to Inflammation
}

\author{
Dieter Metze *, Heiko Traupe and Kira Süßmuth \\ Klinik für Hautkrankheiten, Universitätsklinik Münster, 48149 Münster, Germany; \\ traupeh@ukmuenster.de (H.T.); Kira.Suessmuth@ukmuenster.de (K.S.) \\ * Correspondence: metzed@uni-muenster.de
}

check for

updates

Citation: Metze, D.; Traupe, H.; Süßmuth, K. Ichthyoses-A Clinical and Pathological Spectrum from Heterogeneous Cornification Disorders to Inflammation. Dermatopathology 2021, 8, 107-123. https://doi.org/10.3390/ dermatopathology 8020017

Academic Editors: Sylvie Fraitag and Gürkan Kaya

Received: 6 April 2021

Accepted: 28 April 2021

Published: 7 May 2021

Publisher's Note: MDPI stays neutral with regard to jurisdictional claims in published maps and institutional affiliations.

Copyright: (c) 2021 by the authors. Licensee MDPI, Basel, Switzerland. This article is an open access article distributed under the terms and conditions of the Creative Commons Attribution (CC BY) license (https:// creativecommons.org/licenses/by/ $4.0 /)$.

\begin{abstract}
Ichthyoses are inborn keratinization disorders affecting the skin only (non-syndromic) or are associated with diseases of internal organs (syndromic). In newborns, they can be life-threatening. The identification of the gene defects resulted in reclassification and a better understanding of the pathophysiology. Histopathologic patterns include orthohyperkeratosis with a reduced or welldeveloped stratum granulosum, hyperkeratosis with ortho- and parakeratosis with preserved or prominent stratum granulosum, and epidermolytic ichthyosis. Another pattern features "perinuclear vacuoles and binucleated keratinocytes", which is associated with keratin mutations. Some ichthyoses are histologically defined by psoriasis-like features, and distinct subtypes show follicular hyperkeratosis. In addition to histological and immunohistochemical methods, these patterns allow a better histopathologic diagnosis.
\end{abstract}

Keywords: ichthyosis; hereditary keratinization disorders; dermatopathology; pattern analysis; immunohistochemistry

\section{Target Readership}

The article was written for dermatologists and pathologists interested in genodermatoses and dermatohistology, especially the diagnosis of ichthyoses. It is supposed to help to diagnose different types of ichthyoses when genetic analyses are not available or before genetic testing.

\section{Introduction}

Ichthyoses are hereditary keratinization disorders defined by universal scaling occurring over the entire body. Some forms manifest at birth ("congenital" forms), others during the first year of life ("vulgar" forms) (Table 1) [1,2].

An accurate and rapid diagnosis of a hereditary keratinization disorder is important to identify associated diseases of internal organs in syndromic forms (Table 1), to initiate genetic counseling, and to start potential therapies [1,2].

The histopathology of ichthyoses is mentioned in publications and book chapters [3] but has not been systematically studied and is often considered "nonspecific." Traditionally, therefore, the clinical picture, family history, and occasionally laboratory chemistry and electron microscopic studies have been crucial for diagnosis. Only the identification of the genetic causes has led to an understanding of the molecular mechanisms, as well as to the reclassification of these genodermatoses (Table 1) [4,5]. Assistance is provided by special networks (www.netzwerk-ichthyose.de (accessed on 3 May 2021)) and patient support-groups (https:/ / www.ichthyose.de/ (accessed on 3 May 2021)).

In parallel, the pathological changes of the skin biopsies were characterized in more detail. Certain histological patterns could be defined. They include the following criteria: hyperkeratosis with/without parakeratosis, expression/absence of the stratum granulosum, atrophy/hyperplasia (acanthosis) of the epidermis, vacuolization/eosinophilic granules in keratinocytes, or hyperkeratosis and a degree of development of hair follicles. 
Complementary histo- and immunohistochemical methods allow for, in part, a precise diagnosis, but at least a limitation of differential diagnoses, which can then be further clarified by targeted mutation analyses [6,7].

Table 1. Clinical classification of ichthyoses.



In the following, the dermatopathological diagnosis is presented on the basis of some frequent, but also rare syndromic and life-threatening ichthyoses, which can be performed quickly, easily, and economically on sample biopsies of the skin. Hereditary keratinization disorders are also discussed. They often show a highly inflammatory, psoriasis-like picture and are therefore often misdiagnosed (Table 2) [6,8].

Table 2. Ichthyoses with a psoriasis-like picture.

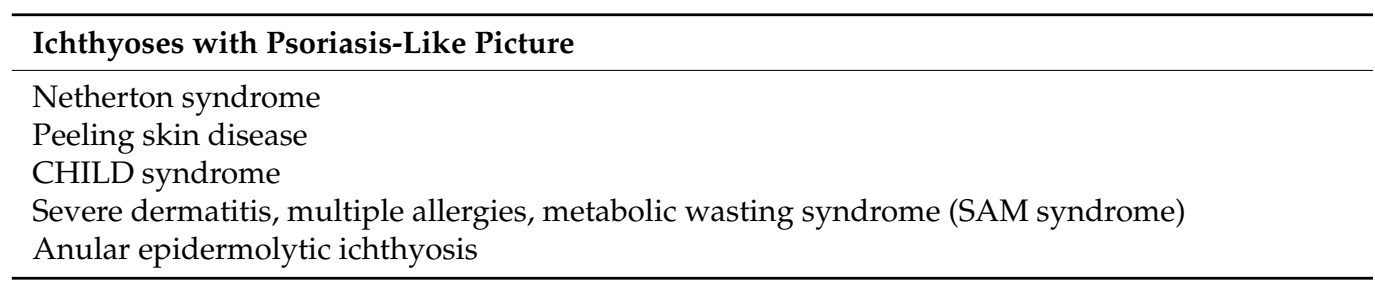

\section{Ichthyosis Vulgaris}

The autosomal semidominant inherited ichthyosis vulgaris is the most frequent ichthyosis (prevalence from 1:100 to 1:250) [9]. It usually develops in the course of the first year of life and manifests with dry skin or light gray fine scales (Figure 1) as well as palmoplantar hyperlinearity. The disorder is caused by loss-of-function mutations in the filaggrin gene (Table 3). Filaggrin is expressed in the keratohyalin granules and crosslinks 
the keratin filaments in the horny layer. A deficiency of filaggrin predisposes to atopic dermatitis and/or allergic rhinoconjunctivitis [8,10]. Interestingly, filaggrin mutations can also be observed in X-linked recessive ichthyosis underlying steroid sulfatase deficiency [10].

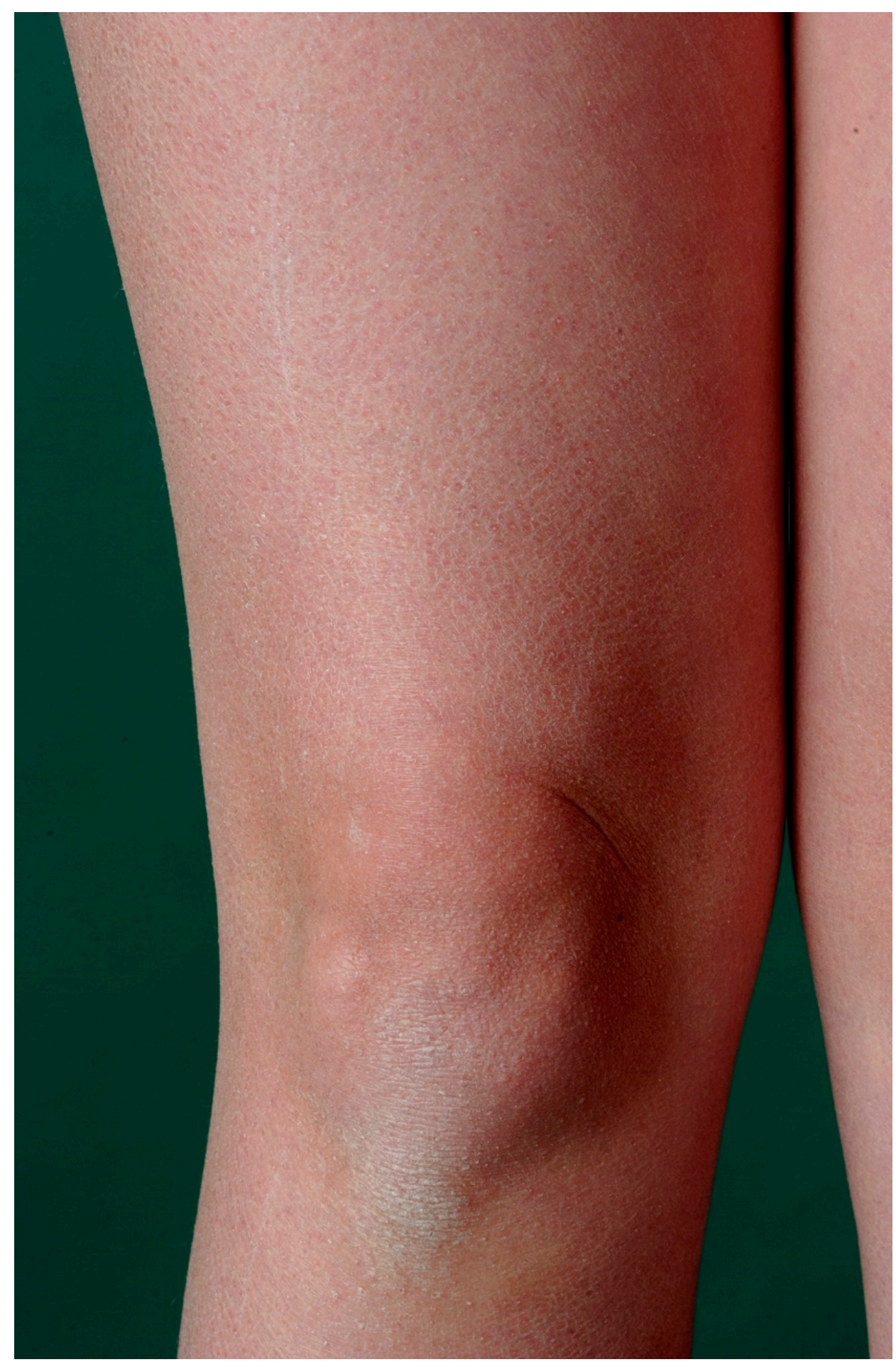

Figure 1. Ichthyosis vulgaris. Fine grey scaling on the extremities. 
Table 3. Different types of ichthyosis with gene mutation and mode of inheritance.

\begin{tabular}{|c|c|c|c|c|}
\hline & \multirow{3}{*}{ Common Ichthyoses } & \multicolumn{2}{|l|}{ Ichthyosis } & $\begin{array}{l}\text { Gene } \\
\text { (mode of inheritance) }\end{array}$ \\
\hline & & \multicolumn{2}{|l|}{ Ichthyosis Vulgaris } & $\begin{array}{l}\text { FLG (filaggrin) } \\
\text { (autosomal semidominant) }\end{array}$ \\
\hline & & \multicolumn{2}{|l|}{ X-Linked Ichthyosis } & $\begin{array}{l}\text { STS (steroid sulfatase) } \\
\text { (X-linked recessive) }\end{array}$ \\
\hline \multirow{6}{*}{$\begin{array}{l}\text { Non-Syndromic } \\
\text { Ichthyoses }\end{array}$} & \multirow{6}{*}{$\begin{array}{l}\text { ARCI and } \\
\text { Keratinopathic } \\
\text { Ichthyoses }\end{array}$} & \multicolumn{2}{|l|}{ Harlequin Ichthyosis } & $\begin{array}{l}\text { ABCA12 (ATP Binding Cassette Subfamily A } \\
\text { Member 12) } \\
\text { (autosomal recessive) }\end{array}$ \\
\hline & & \multicolumn{2}{|c|}{$\begin{array}{l}\text { Lamellar Ichthyosis, Congenital Ichthyosiform } \\
\text { Erythroderma }\end{array}$} & $\begin{array}{l}\text { TGM1 (transglutaminase-1); } \\
\text { ALOX12B (Arachidonate 12-Lipoxygenase, } \\
\text { 12R Type); ALOXE3 (Arachidonate } \\
\text { Lipoxygenase 3); CYP4F22 (Cytochrome P450 } \\
\text { Family } 4 \text { Subfamily F Member 22); NIPAL4 } \\
\text { (Ichthyin) and others } \\
\text { (autosomal recessive) }\end{array}$ \\
\hline & & \multicolumn{2}{|l|}{ Bathing Suit Ichthyosis } & $\begin{array}{l}\text { TGM1 } \\
\text { (autosomal recessive) }\end{array}$ \\
\hline & & \multirow[t]{2}{*}{ Keratinopathic Ichthyoses } & EI & $\begin{array}{l}\text { KRT1 (keratin 1); } \\
\text { KRT10 (keratin 10) } \\
\text { (autosomal dominant, sometimes recessive } \\
\text { (KRT10 mutations) }\end{array}$ \\
\hline & & & SEI & $\begin{array}{l}\text { KRT2 (keratin 2) } \\
\text { (autosomal dominant) }\end{array}$ \\
\hline & & Rare Variants of KPI & CRIE & $\begin{array}{l}\text { KRT1 } \\
\text { KRT10 } \\
\text { (autosomal dominant, de novo mutations) } \\
\end{array}$ \\
\hline \multirow{2}{*}{\multicolumn{2}{|c|}{ Further Non-Syndromic Ichthyoses }} & \multicolumn{2}{|l|}{ Peeling Skin Disease } & $\begin{array}{l}\text { CDSN (corneodesmosin) } \\
\text { (autosomal recessive) }\end{array}$ \\
\hline & & \multicolumn{2}{|c|}{ Erythrokeratoderma Variabilis } & $\begin{array}{l}\text { GJB3 (encoding Connexin 31) } \\
\text { GJB4 (encoding Connexin 30.3) } \\
\text { (often autosomal dominant) }\end{array}$ \\
\hline \multirow{4}{*}{\multicolumn{2}{|c|}{ Syndromic Ichthyoses }} & \multicolumn{2}{|l|}{ Netherton Syndrome } & $\begin{array}{l}\text { SPINK5 (encoding LEKTI) } \\
\text { (autosomal recessive) }\end{array}$ \\
\hline & & \multicolumn{2}{|l|}{ KID Syndrome } & $\begin{array}{l}\text { GJB2 (encoding Connexin 26) } \\
\text { (autosomal dominant) }\end{array}$ \\
\hline & & \multicolumn{2}{|l|}{ CHILD Syndrome } & $\begin{array}{l}\text { NSDHL }(N A D(P) \text { Dependent Steroid } \\
\text { Dehydrogenase-Like) } \\
\text { (x-linked dominant) }\end{array}$ \\
\hline & & \multicolumn{2}{|l|}{ SAM Syndrome } & $\begin{array}{l}\text { DSG1 (desmoglein-1) } \\
\text { DSP (desmoplakin) } \\
\text { (autosomal recessive) }\end{array}$ \\
\hline
\end{tabular}

\subsection{Histology}

A characteristic feature of ichthyosis vulgaris is a markedly reduced, often completely absent stratum granulosum. The stratum corneum exhibits mild compact orthohyperkeratosis (Figure 2). Frequently, there is also hyperkeratosis of hair follicles and acrosyringia. The epidermis may be slightly widened (acanthotic) but also atrophic. Isolated mild perivascular lymphocytic infiltrates can be found in the dermis. Associated signs of spongiform dermatitis may be encountered in the setting of atopy.

Immunohistochemically, a deficiency of filaggrin can be quantified, which correlates with the number of mutations (one or two mutations in the filaggrin gene) and thus, the severity of ichthyosis. Ultrastructurally, there is a defect in the keratohyalin granules, which appear diminished and crumbly. 


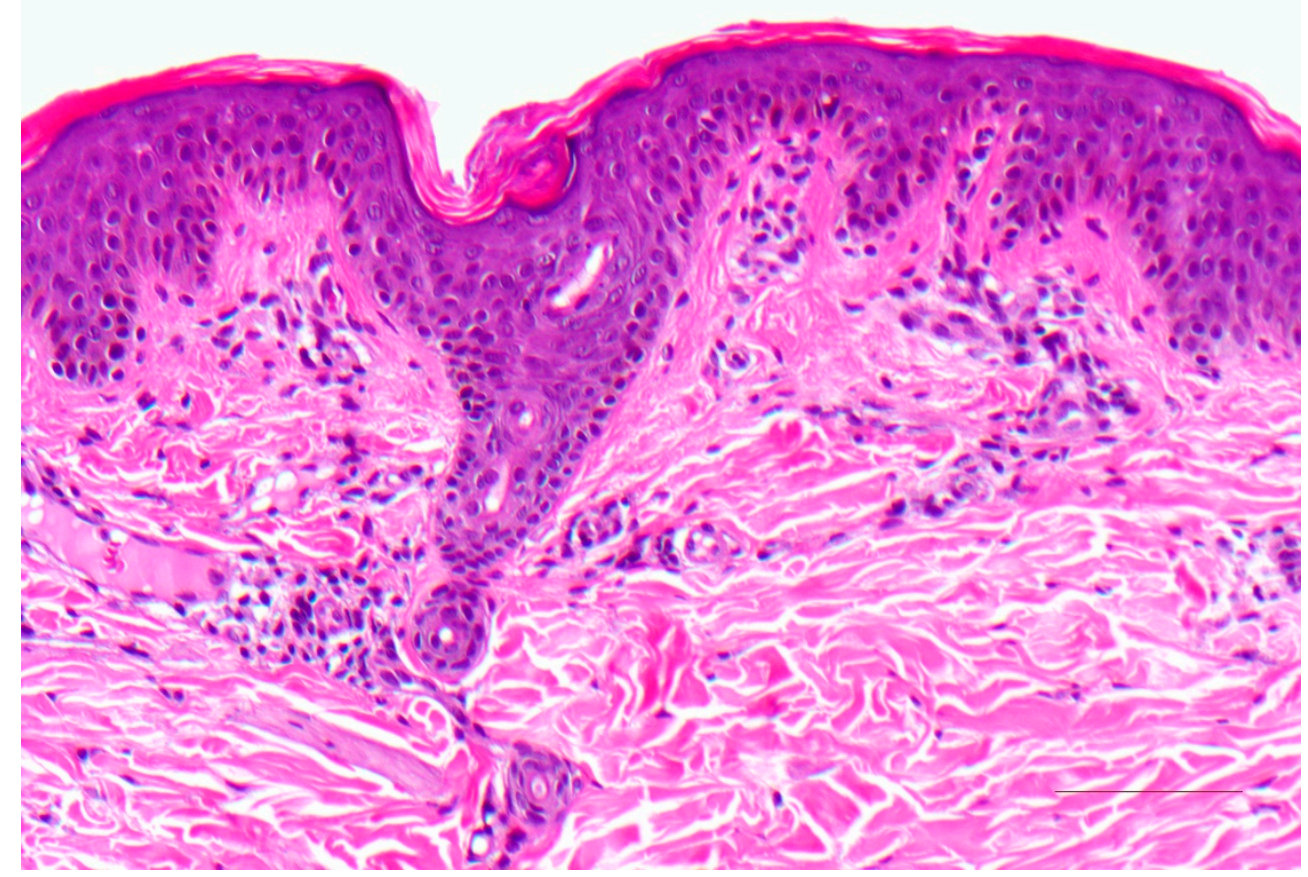

Figure 2. Ichthyosis vulgaris. Note the absent stratum granulosum and mild compact orthohyperkeratosis. Marked hyperkeratosis of the opening of the acrosyringium. Inflammatory infiltrates are almost absent. HE stain, bar $=100 \mu \mathrm{m}$.

\subsection{Differential Diagnoses}

A thinned or absent stratum granulosum with mild orthohyperkeratosis is also observed in patients with atopy and other very rare ichthyoses, such as Conradi-HünermannHapple syndrome [6]. It can also be found in acquired ichthyosis-like skin conditions ("acquired ichthyoses"). Causes are malignancies (lymphomas), renal insufficiency, Crohn's disease, autoimmune diseases (collagenoses), GvHD, infections (HIV, leprosy), endocrinopathies (hypothyroidism), sarcoidosis, malnutrition (vitamin A) or drugs (lipid-lowering drugs, psychotropic drugs) [11].

\section{Autosomal Recessive Congenital Ichthyosis}

Autosomal recessive congenital ichthyosis (ARCI) represents a genetically heterogeneous group of non-syndromic congenital ichthyoses with widely varying severity. The group comprises lamellar ichthyosis, which is most often due to tranglutaminase-1 deficiency (Table 3), congenital ichthyosiform erythroderma, and the most severe but rare subtype of harlequin ichthyosis [12]. Newborns can be born with a tight and shiny stratum corneum, which is associated with ectropion, eclabium, fluid loss, and thermal dysregulation, and resulting in potentially life-threatening complications. However, the clinical presence of a collodion membrane is also encountered in other ichthyoses [5].

Later, the collodion membrane is replaced by dark brown, adherent, plate-like scales (classic lamellar ichthyosis; Figure 3) or a whitish, poorly adherent, fine scale on reddened skin (non-bullous congenital ichthyosiform erythroderma). To varying degrees, there are associated palmoplantar keratoderma, nail dystrophies, fibrosing alopecia, and hypohidrosis with heat intolerance [5]. 


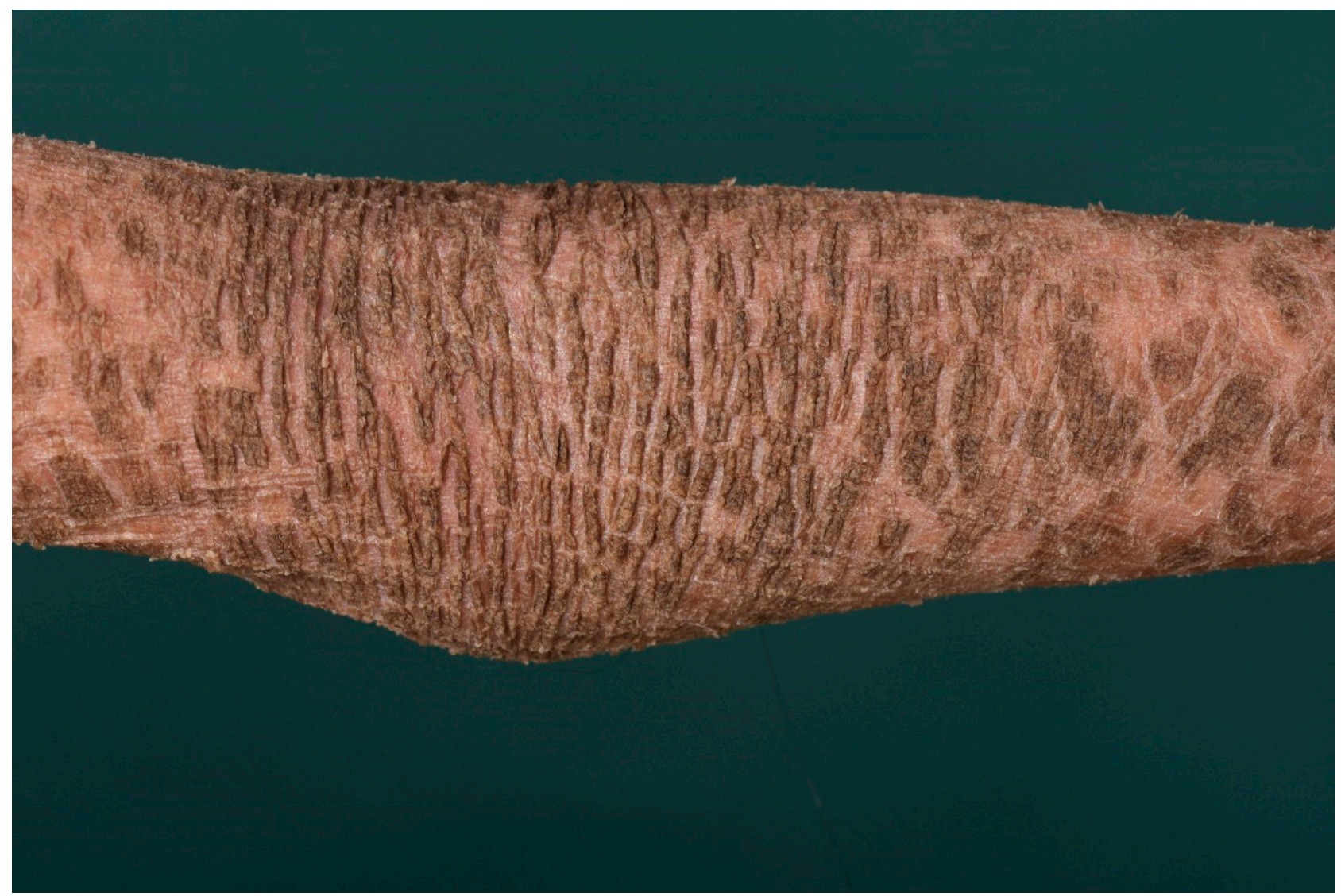

Figure 3. Lamellar ichthyosis. Dark brownish lamellar scaling in a patient with transglutaminase-1 deficiency.

The ARCI forms are caused by different mutations. In $30-40 \%$ of cases, a mutation is present in the transglutaminase - 1 gene, resulting in a disruption of protein cross-linking and the esterification of ceramides in corneocytes. Using biotinylated donor substrates, such as the amine donor monodansylcadaverine, transglutaminase activity can be visualized immediately in situ by fluorescence labeling based on the incorporation of monodansylcadaverine on sections of unfixed frozen biopsies [13]. Mutations are also present in the $A T B$-binding cassette transporter ( $A B C A 12)$ gene, which, unlike harlequin-ichthyosis, has residual activity in milder ARCI cases. ABCA12 is required in epidermal lipid transport via the lamellar bodies. Other mutations involve the ichthyin, lipoxygenase, or cytochrome P450 oxidase genes FLJ39501. A definitive correlation of this mutation with a specific phenotype of ARCI has not been fully established [8].

\subsection{Histology}

Histologically, there is compact orthohyperkeratosis, a slightly widened stratum granulosum, acanthosis, and papillomatosis of the epidermis. In the papillary body, the vessels appear dilated and spiraling, and lymphocytic infiltrates are scarce or mild (Figure 4) [7].

\subsection{Differential Diagnoses}

The various forms of ARCI cannot be differentiated histologically, except for harlequin ichthyosis. Similarly, X-linked ichthyosis presents with almost identical pathology. Lichen simplex chronicus presents with more severe inflammation and fibrosis in the papillary body. 


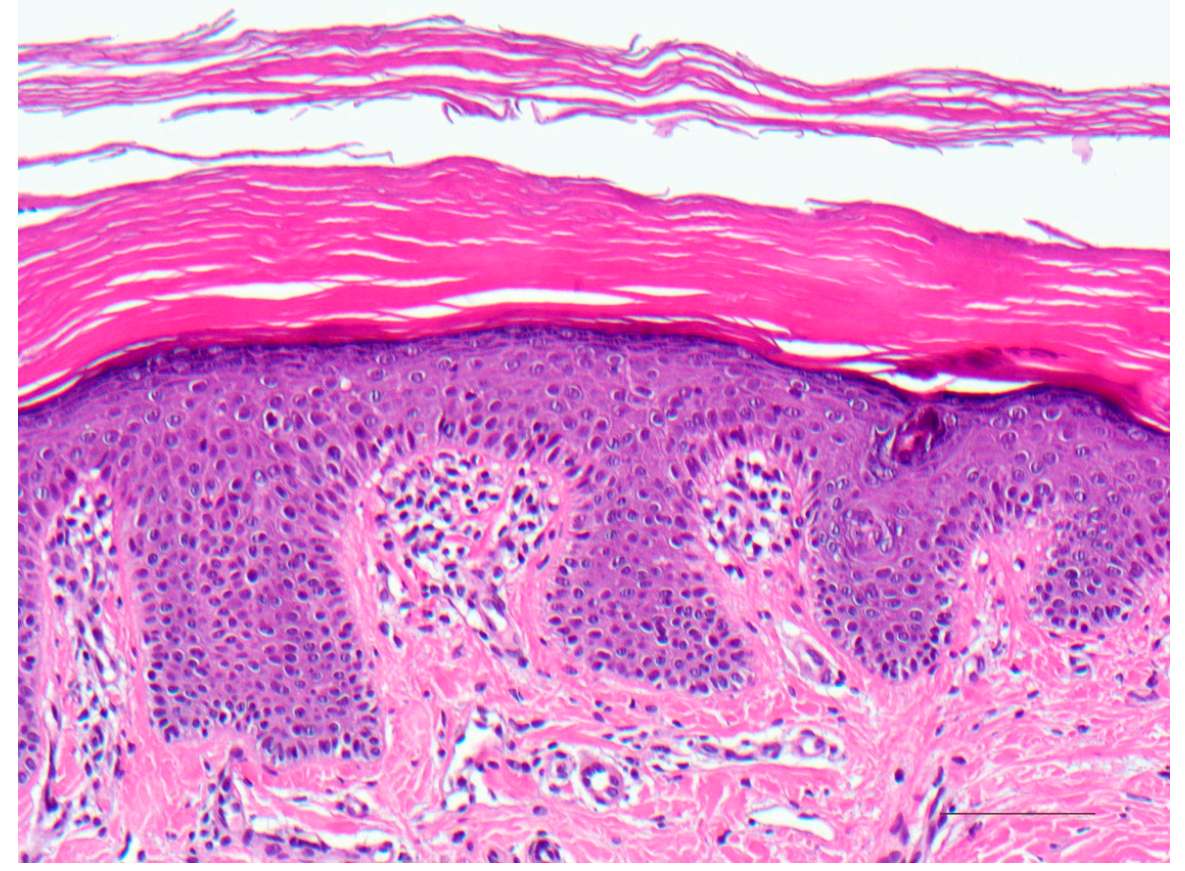

Figure 4. Autosomal recessive lamellar ichthyosis. Acanthotic epidermis with well-developed stratum granulosum and compact orthohyperkeratosis without further signs of inflammation. HE stain, original magnification, bar $=100 \mu \mathrm{m}$.

\section{Keratinopathic Ichthyosis}

Epidermolytic ichthyosis, formerly also called bullous congenital ichthyotic erythroderma Brocq, is due to a mutation of keratin 1 or keratin 10 and is therefore classified as keratinopathic ichthyosis (Table 3) [5]. Neonates present with erythroderma with blistering, sometimes pronounced, and later develop (spiky) keratoses, preferentially on the extremities (Figure 5). Patients with a keratin 1 mutation also have palmoplantar keratosis, which is absent in patients with a keratin 10 mutation because this keratin is not expressed there [14].

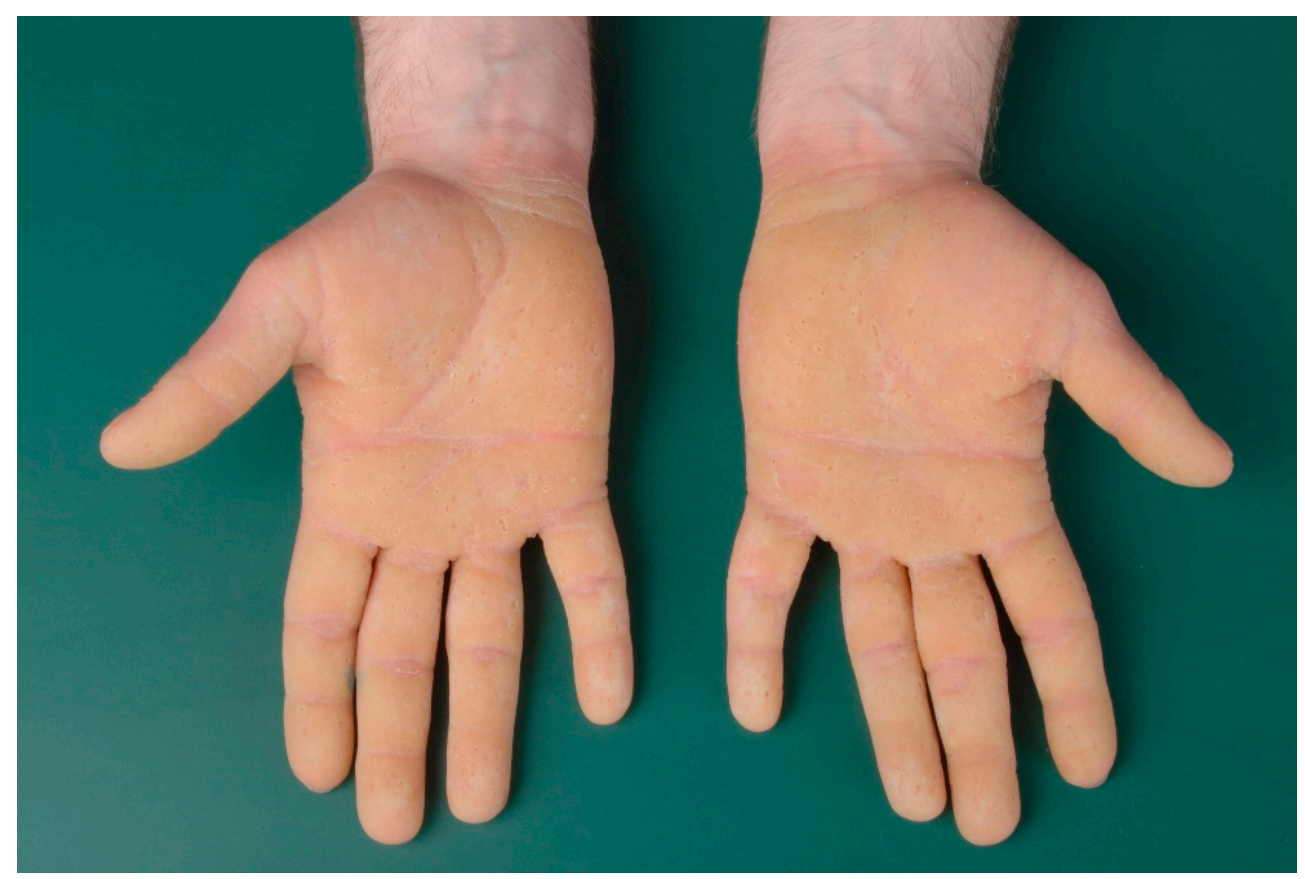

Figure 5. Epidermolytic ichthyosis. Diffuse palmoplantar keratoderma (keratin 1 mutation). 


\subsection{Histology}

There is massive orthohyperkeratosis and acanthosis of the epidermis. The suprabasal keratinocytes reveal vacuolization and distinct hypereosinophilic granules. In the stratum granulosum, the keratohyalin granules are coarse and irregular. The boundaries between keratinocytes are poorly demarcated, and clefts and blisters occur. Minor lymphocytic infiltrates may impose in the dermis (Figure 6) [8].

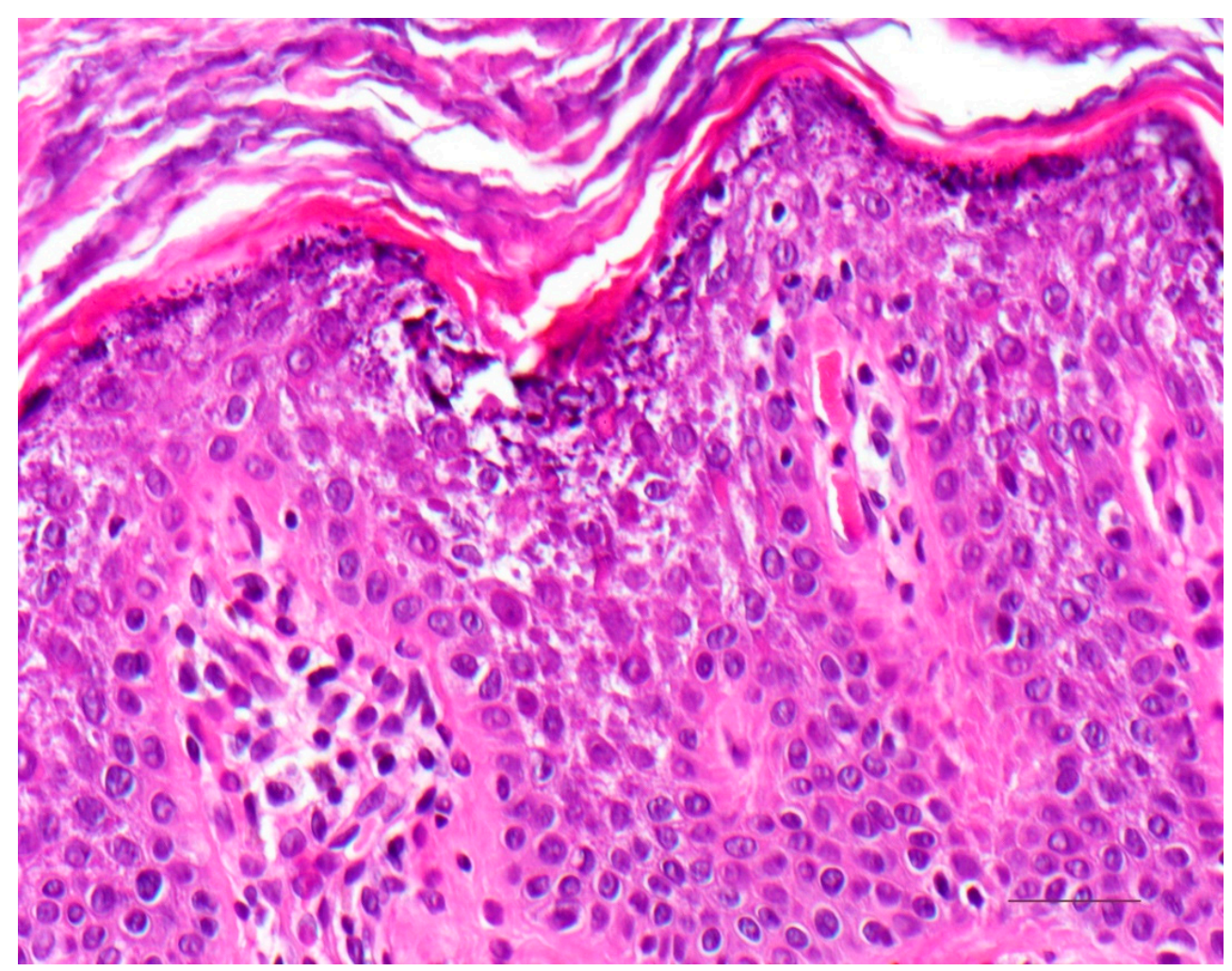

Figure 6. Epidermolytic ichthyosis. Acanthotic epidermis with massive orthohyperkeratosis. Suprabasal keratinocytes vacuolated with distinct hypereosinophilic granules and irregular keratohyalin granules. HE stain, bar $=50 \mu \mathrm{m}$.

Electron microscopically, the hypereosinophilic granules correspond to clumps of the keratin skeleton. A collapse of the mutant keratins causes the vacuolar aspect of the cytoplasm and results in mechanical instability.

\subsection{Differential Diagnoses}

The histologic reaction pattern of epidermolytic hyperkeratosis is also found in superficial epidermolytic ichthyosis with a keratin 2 mutation (ichthyosis bullosa Siemens), or epidermal nevi in the setting of mosaicism of keratinopathic ichthyoses $[15,16]$. Very discrete and circumscribed, these changes are also found incidentally in normal skin (preferentially in the vicinity of epithelial or melanocytic tumors), as well as in cysts, scars, or various inflammatory dermatoses.

\section{Erythrokeratoderma}

Erythrokeratodermas are defined by localized erythematous keratoses on the body and are now classified in the ichthyosis group [5]. They are caused by mutations of connexin 30.3 or 31 (Table 3). These transmembrane protein gap junctions are essential for intercellular communication and, thus, for epidermal differentiation [17].

Autosomal dominantly inherited erythrokeratodermia variabilis (Mendes da Costa syndrome) initially manifests with migratory figured erythema, and later persistent keratoses. The expression varies between intra- and interfamilial, and sometimes only circum- 
scribed keratoses are found on pressure-exposed areas of the sole of the foot. Progressive symmetric erythrokeratodermia (Gottron) is no longer distinguished as a separate entity from erythrokeratodermia variabilis [18].

\section{Histology}

The epidermis shows acanthosis and undulating surface with hyperkeratosis, focal parakeratosis, dyskeratotic keratinocytes, and preserved stratum granulosum. Superficial perivascular lymphocytic infiltrate may be present (Figure 7). Overall, the histologic changes mentioned are highly variable and complicate diagnosis. The deficiency of the affected connexin can be easily visualized by immunohistochemistry; at the same time, compensatory connexin 43 expression is increased.

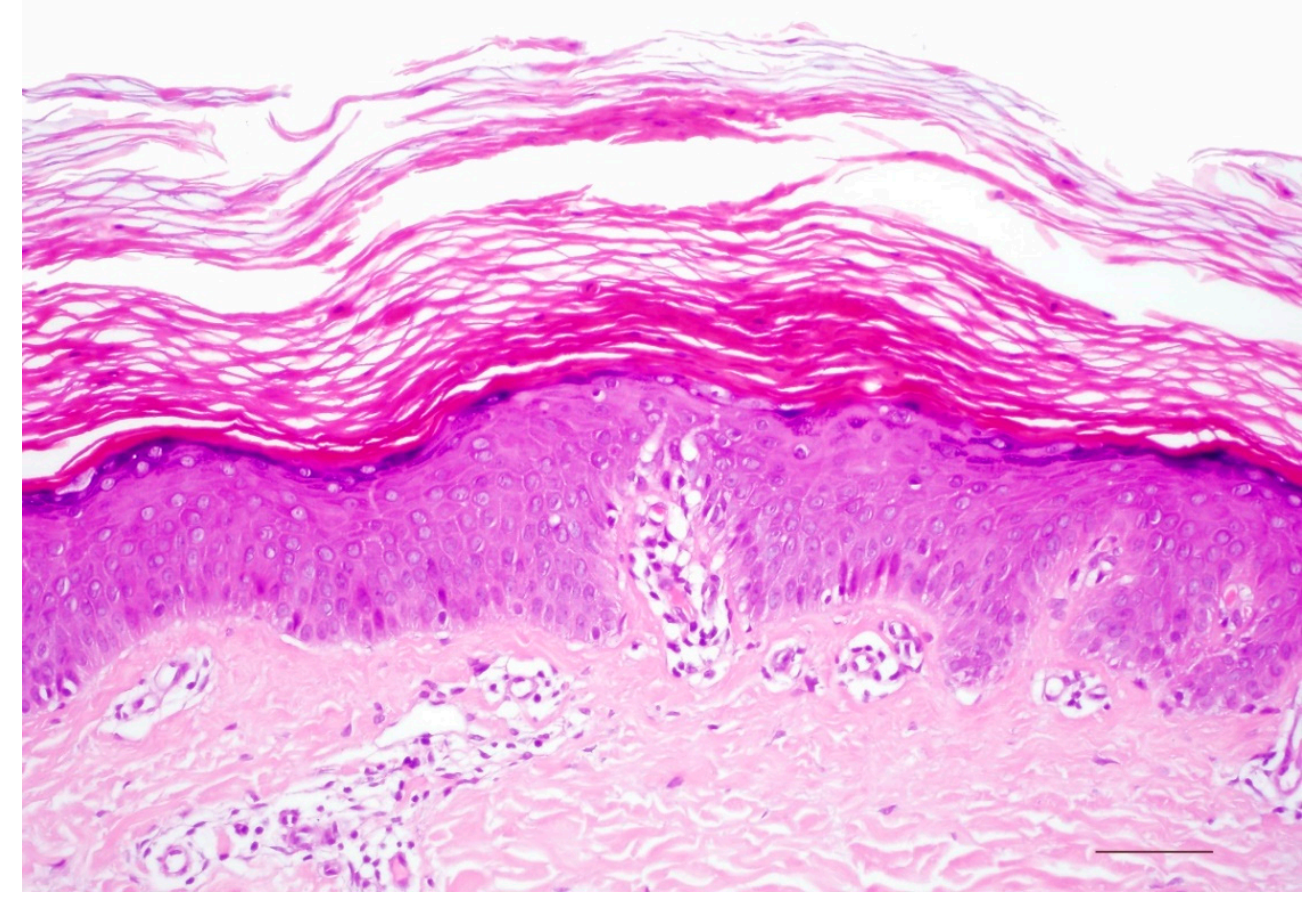

Figure 7. Erythrokeratoderma. Acanthotic epidermis with orthohyperkeratosis, focal parakeratosis, dyskeratotic keratinocytes, and preserved stratum granulosum. Discrete superficial perivascular lymphocytic infiltrate. HE stain, bar $=100 \mu \mathrm{m}$.

\section{KID Syndrome and HID Syndrome}

Keratitis-ichthyosis-deafness (KID) syndrome and hystrix-like-ichthyosis-deafness (HID) syndrome are different forms of an autosomal dominant inherited ichthyosis caused by a mutation of connexin 26 (Table 3) [19]. Because this connexin performs important functions in the inner ear, neurosensory hearing loss also exists. Patients with KID syndrome develop sharply circumscribed wart-like hyperkeratotic plaques on the face and extremities; in HID syndrome, hystrix-like generalized ichthyosis predominates. In the setting of this syndromic ichthyosis, keratitis, alopecia, nail dystrophy, dental abnormalities, or hypohidrosis, and an increased risk of infection and carcinoma occur.

\subsection{Histology}

The epidermis is acanthotic with a partially verruciform appearance. The hyperkeratotic stratum corneum contains parakeratoses with large round nuclear remnants, and occasionally shadow cells with vacuolated nuclei (Figure 8). Dyskeratotic keratinocytes with perinuclear halo ("bird's eye") appear as a dominant criterion. The stratum granulosum may be absent or strongly pronounced. Subepidermal dense lymphocytic infiltrates occur in some cases. The openings of the hair follicles and sweat glands are highly keratinized. 
The sweat glands may be diminished and atrophic. Highly differentiated squamous cell carcinoma may also occur at a young age [8].

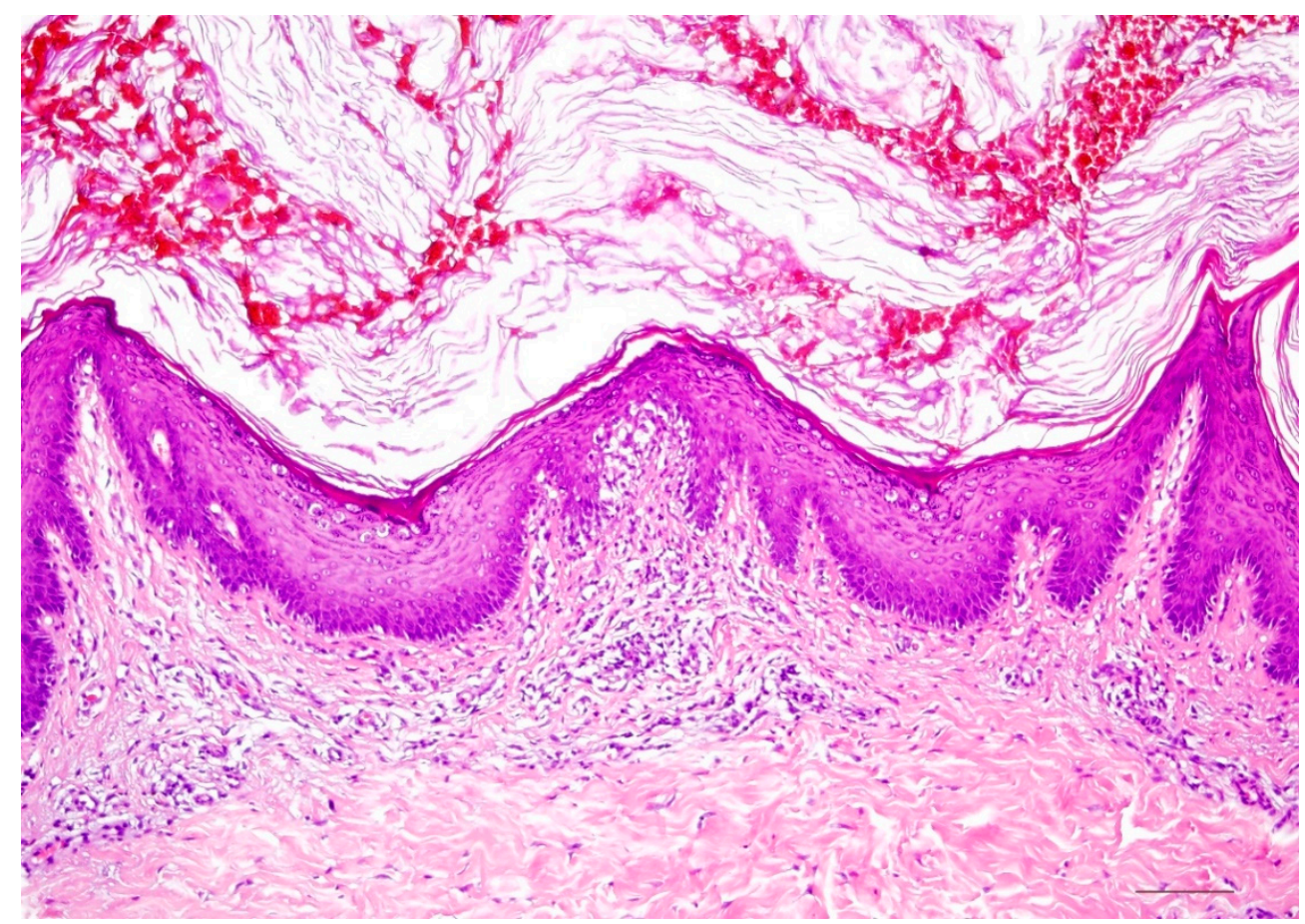

Figure 8. KID syndrome (keratitis-ichthyosis-deafness). Dyskeratotic keratinocytes with perinuclear halo ("bird's eye"). HE stain, bar $=100 \mu \mathrm{m}$.

\subsection{Differential Diagnoses}

Verrucae vulgares also show vacuolated cells, but in KID/HID syndrome these persist in the stratum corneum. Vacuolization is absent in erythrokeratodermia.

\section{Ichthyoses with Inflammatory Psoriasiform Pattern}

Some hereditary ichthyoses have a histologic pattern that closely resembles psoriasis vulgaris or chronic dermatitis in the setting of atopic eczema, which is why misdiagnosis is common (Table 2). Because of the significant and sometimes lethal complications associated with this group of ichthyoses, prompt dermatohistologic diagnosis is important [20].

\section{Netherton Syndrome}

In autosomal recessive Netherton syndrome, there is a mutation of the SPINK5 gene, which encodes LEKTI ("lymphoepithelial Kazal-type related inhibitor"), a major serine protease inhibitor of the epidermis and thymus (Table 3) [21]. Patients are born with marked erythroderma, which later often changes into anular eyrthema with a typical double-edged scale ("ichthyosis linearis circumflexa") (Figure 9). Later, brittle hairs are also noticeable ("bamboo hairs", trichorrhexis invaginata). Type 1 allergies, elevated IgE levels, and hypereosinophilia, as well as immunodeficiency and enteropathy, which can lead to massive failure to thrive, especially in the first year of life, are associated with this cornification disorder. Electrolyte disturbances and sepsis are lethal risks for infants. 


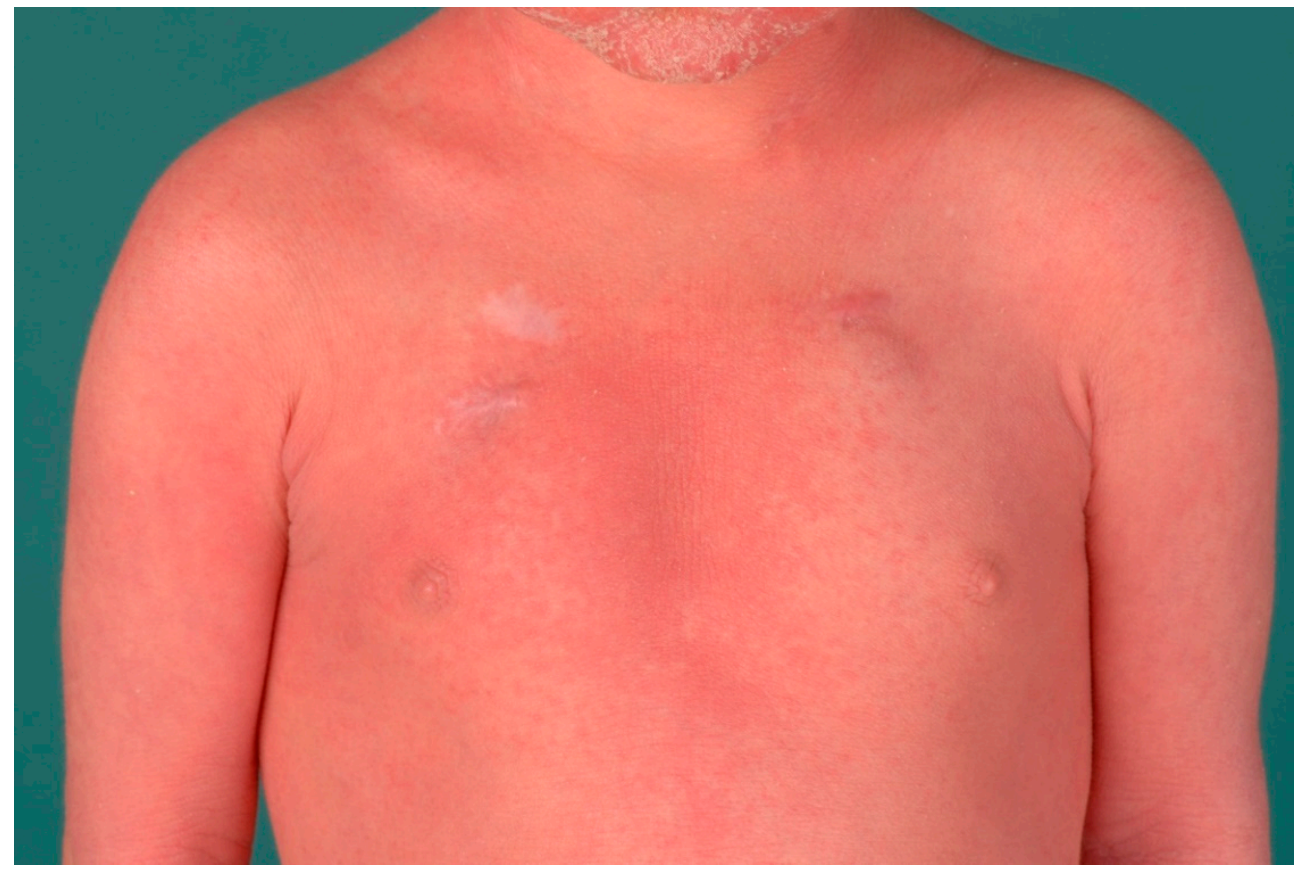

Figure 9. Netherton syndrome. Erythema and scaling of the trunk and face.

\subsection{Histology}

There is psoriasiform hyperplasia with a moderately widened stratum corneum showing focal parakeratosis and accumulations of neutrophils. The stratum granulosum is absent or severely diminished. The papillary dermis is papillomatously elongated and contains dilated vessels and inflammatory infiltrates with lymphocytes, neutrophils, and eosinophilic granulocytes (Figure 10). Sometimes, however, there are histologic changes, as found in atopic dermatitis. Immunohistochemically, staining for LEKTI is absent in the epidermis and hair follicles (Figure 11) [22].

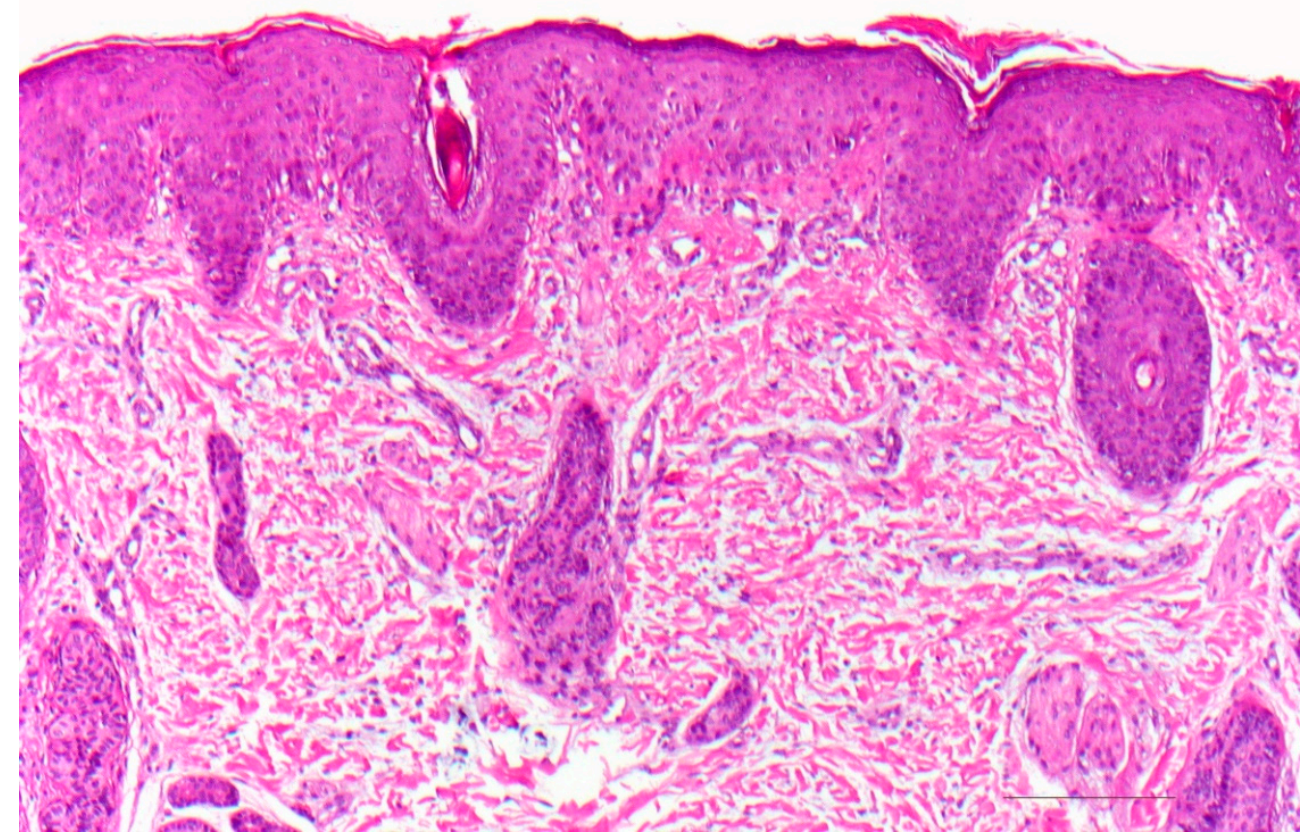

Figure 10. Netherton syndrome. Regular (psoriasiform) hyperplasia with focal parakeratosis and thinned stratum granulosum. Dilated vessels in the papillary dermis and inflammatory infiltrates. HE stain, bar $=100 \mu \mathrm{m}$. 




(a)

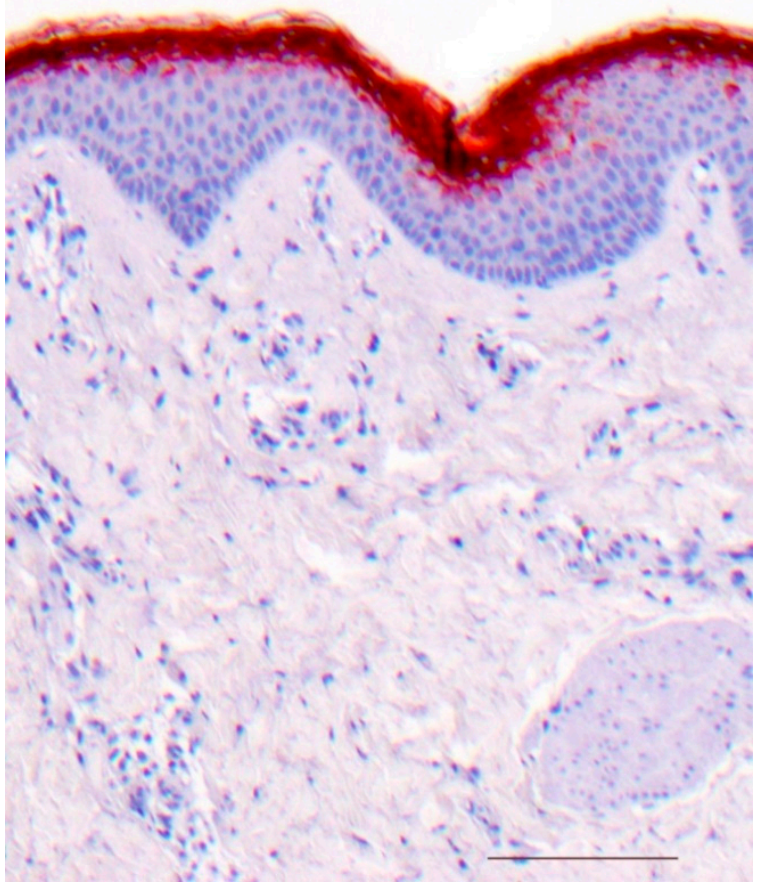

(b)

Figure 11. Netherton syndrome, immunohistochemistry, bar $=200 \mu \mathrm{m}(\mathbf{a}, \mathbf{b})$. Immunohistochemistry shows a lack of staining for LEKTI in the epidermis and hair follicles (a); regular expression of LEKTI in the upper layers of the epidermis of healthy skin, bar $=200 \mu \mathrm{m}(\mathbf{b})$. Immunoperoxidase staining.

\subsection{Differential Diagnoses}

Psoriasis vulgaris or atopic dermatitis cannot always be differentiated histologically. PAS-positive granules in the stratum corneum cannot always be detected and are not specific. The immunohistochemically detectable lack of LEKTI expression is important evidence for Netherton syndrome. Other forms of ichthyosis with psoriasis-like histology are listed in Table 2.

\section{Peeling Skin Disease}

In peeling skin disease (peeling skin syndrome B), generalized erythema with superficial skin detachment is evident from birth and persists throughout life with seasonal variation (Figure 12). In addition, episodic detachment of the nail plates (onychomadesis) may occur. Hair status is inconspicuous except for a transient slight epilation of fine hairs [23].

There is a mutation of corneodesmosin, an important adhesion protein expressed in the extracellular sections of desmosomes in the stratum corneum of the epidermis, as well as at the inner hair root sheath of hair follicles (Table 3). Ultrastructurally, there is detachment of intact corneocytes from the stratum granulosum (extracellular cleft formation) [20,23]. Autosomal dominant mutations in other domains of corneodesmosin cause hypotrichosis simplex.

Concomitant barrier disruption leads to inflammation with massive pruritus, urticaria, angioedema, food allergy, and asthma with elevated IgE levels and blood eosinophilia. 




Figure 12. Peeling skin disease. Diffuse erythema with superficial skin detachment is evident from birth and persists throughout life with seasonal variation.

\subsection{Histology}

The epidermis is hyperplastic with prominent rete ridges. There is mild hyperkeratosis with focal parakeratosis and thinned stratum granulosum. Some biopsies show a focal detachment of the stratum corneum, and in some cases, the stratum corneum is completely absent. However, these changes cannot always be detected on a paraffin section. There are superficial and perivascular lymphocytic infiltrates with single neutrophils, which are also found in the stratum corneum. The papillary body is elongated and edematous, vessels are not dilated [7]. Immunohistochemically, staining for corneodesmosin is absent in the stratum corneum [23].

\subsection{Differential Diagnosis}

Psoriasis vulgaris, Netherton syndrome, and CHILD syndrome cannot be differentiated without immunohistochemistry.

\section{CHILD Syndrome}

Congenital Hemidysplasia with Ichthyosiform nevus and Limb Defect (CHILD) syndrome is a very rare $\mathrm{X}$-linked dominant disorder that is usually lethal for male offspring. It is characterized by unilateral inflammatory, often waxy, yellow skin lesions, emphasized in the large flexures and perianogenital region $[8,24]$. Extracutaneous symptoms range from discrete hypoplasia of the limbs to severe deformities. Monosymptomatic cases are often misdiagnosed as psoriasis or ILVEN [25].

The disorder is caused by nonsense or missense mutations in the so-called NSDHL gene, which lead to a disturbance of cholesterol biosynthesis (Table 3) [26,27].

\subsection{Histology}

Hyperplastic epidermis with elongated rete ridges and marked orthohyperkeratosis with focal parakeratosis are found. The stratum granulosum may be prominent in 
some areas but can also be absent. A perivascular lymphocytic infiltrate and xanthomatous macrophages that are markedly immunoreactive for adipophilin are apparent in the papillary body [7].

\subsection{Differential Diagnoses}

Verruciform xanthomas also contain xanthomatous macrophages, which are absent in the other major differential diagnoses as psoriasis inversa and epidermal nevus. The presence of verruciform xanthomas or verruciform xanthoma-like changes in the setting of CHILD syndrome is possible.

\section{Severe Dermatitis, Multiple Allergies, Metabolic Wasting Syndrome (SAM Syndrome)}

SAM syndrome was identified as a severe life-threatening genodermatosis by Liat Samuelov et al. in 2013 [28]. The acronym stands for severe dermatitis, multiple allergies, metabolic wasting syndrome. It is caused by a mutation of desmoglein-1 (DSG1) (Table 3), a major desmosomal adhesion molecule also involved in pemphigus disease. Later, a desmoplakin mutation was also identified [29]. The disease is inherited in an autosomal recessive manner; heterozygous carriers of the DSG1 mutation develop only striate palmoplantar keratoderma [30].

Clinically, there is ichthyosiform erythroderma in newborns similar to autosomal recessive lamellar ichthyosis, Netherton syndrome, or peeling skin disease. Other symptoms are pruritus, hypotrichosis, food allergies with elevated IgE, dysphagia, decreased growth, and recurrent skin and respiratory infections. In varying degrees, pustular formation, palmoplantar keratoses, onychodystrophy, dental anomalies, cardiac abnormalities, and eosinophilic esophagitis are found. There is marked inter- and intrafamilial variability [30]. The accompanying inflammation can be explained by proinflammatory activity in keratinocytes in the context of impaired barrier function and downregulated blockage of signal transduction pathways [31]. Furthermore, the intracytoplasmic portion of DSG1 blocks the RAS-RAF signaling pathway and, thus, affects epidermal differentiation [32,33]. Similar to Netherton syndrome, anti-inflammatory therapies with biologics improve the clinical picture (Oji V, unpublished).

\subsection{Histology}

Histologically, there is a superficial lymphocytic dermatitis with hyperplastic epidermis, parakeratosis, and neutrophil granulocytes that strongly resembles psoriasis (psoriasiform dermatitis). However, there are typically dilated intercellular spaces of the epidermis without blistering (Figure 13). Intracellular edema and serum exudate (as in spongiotic dermatitis), and rounding of keratinocytes and pyknosis of nuclei (as in pemphigus disease), hypereosinophilia of cytoplasm (as in M. Darier or Hailey-Hailey), ballooning, and typical viropathic nuclear changes, as in herpes disease, are absent. 


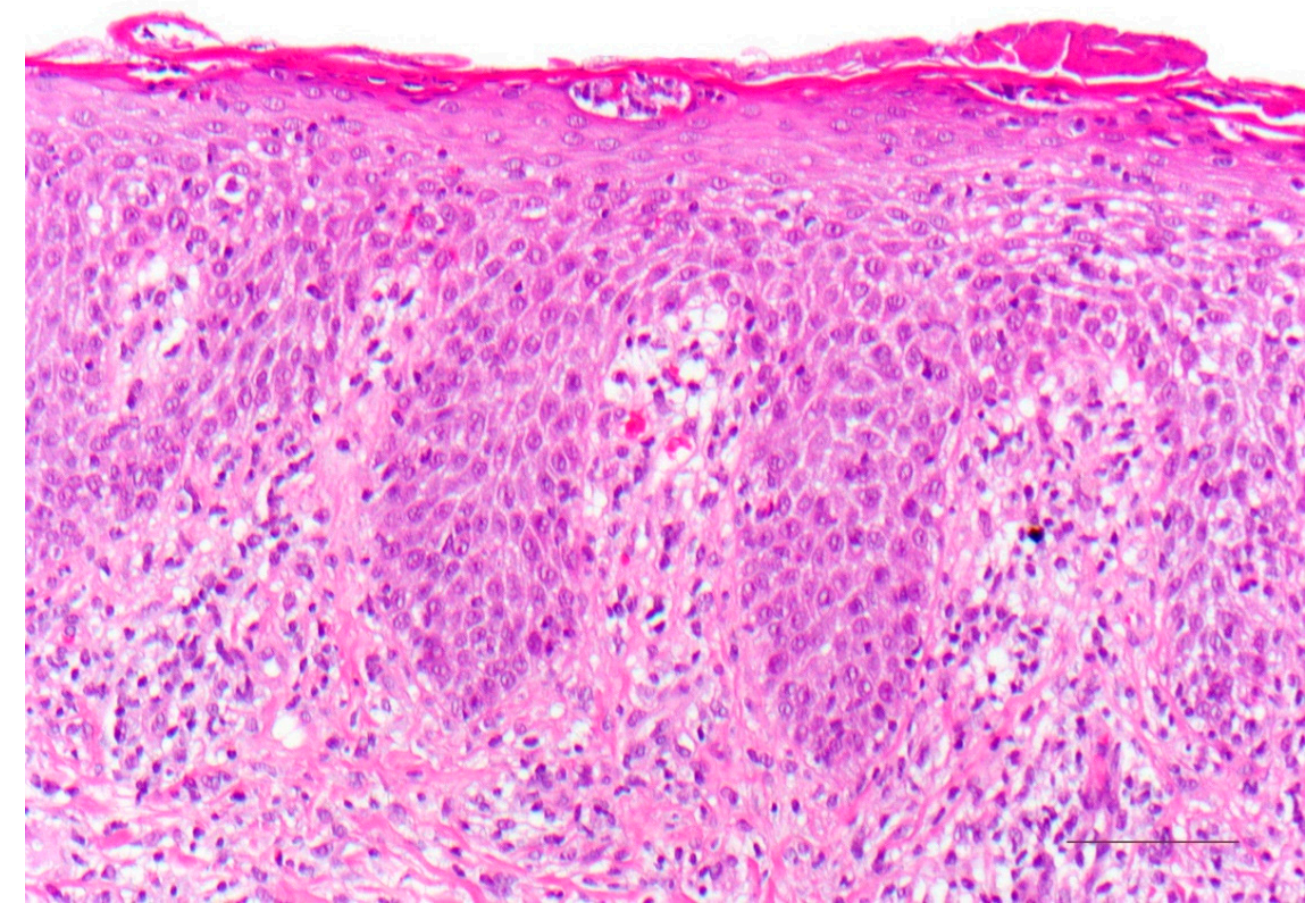

Figure 13. SAM syndrome. Psoriasiform dermatitis with dilated intercellular spaces of the epidermis without blistering ("desmosomal acantholysis"). HE stain, bar $=100 \mu \mathrm{m}$.

\subsection{Differential Diagnoses}

All genodermatoses with mutations of desmosomal proteins leading to the pattern of "desmosomal acantholysis" (Metze, unpublished). These include keratosis palmoplantaris areata et striata (striate palmoplantar keratoderma types 1 and 2), Carvajal-Huerta syndrome, Naxos syndrome, ectodermal dysplasia skin fragility syndrome (McGrath syndrome), or peeling skin disease [34].

Author Contributions: Conceptualization, D.M. and K.S.; methodology, D.M. and K.S.; investigation, D.M., K.S. and H.T.; resources, D.M.; data curation, D.M. and K.S.; writing —original draft preparation, D.M. and K.S.; writing—review and editing, D.M., K.S. and H.T.; visualization, D.M.; supervision, H.T.; project administration, D.M. All authors have read and agreed to the published version of the manuscript.

Funding: This research received no external funding.

Institutional Review Board Statement: Not applicable.

Informed Consent Statement: Not applicable.

Conflicts of Interest: The authors declare no conflict of interest.
Abbreviations
CHILD syndrome
Congenital hemidysplasia with ichthyosiform erythroderma
CRIE and limb defects syndrome
EI
Congenital reticular ichthyosiform erythroderma
KID syndrome
Epidermolytic ichthyosis
Keratitis ichthyosis deafness syndrome
SAM syndrome
Congenital erythroderma-hypotrichosis-recurrent infections-multiple
food allergies syndrome
SEI
Superficial epidermolytic ichthyosis 


\section{References}

1. Krug, M.; Oji, V.; Traupe, H.; Berneburg, M. Ichthyoses-Part 1: Differential diagnosis of vulgar ichthyoses and therapeutic options. J. Dtsch. Dermatol. Ges. 2009, 7, 511-519. [CrossRef]

2. Krug, M.; Oji, V.; Traupe, H.; Berneburg, M. Ichthyoses-Part 2: Congenital ichthyoses. J. Dtsch. Dermatol. Ges. 2009, 7, 577-588. [CrossRef] [PubMed]

3. Traupe, H. The Ichthyoses. In A Guide to Clinical Diagnosis, Genetic Counseling, and Therapy; Springer: Berlin, Germany, 1989; pp. 103-138.

4. Oji, V.; Traupe, H. Ichthyoses: Differential diagnosis and molecular genetics. Eur. J. Dermatol. 2006, 16, 349-359. [PubMed]

5. Oji, V.; Tadini, G.; Akiyama, M.; Blanchet Bardon, C.; Bodemer, C.; Bourrat, E.; Coudiere, P.; DiGiovanna, J.J.; Elias, P.; Fischer, J.; et al. Revised nomenclature and classification of inherited ichthyoses: Results of the First Ichthyosis Consensus Conference in Sorèze 2009. J. Am. Acad. Dermatol. 2010, 63, 607-641. [CrossRef]

6. Metze, D.; Traupe, H. Hereditäre Verhornungsstörungen und epidermale Fehlbildungen. In Histopathologie der Haut, 2nd ed.; Cerroni, L., Garbe, C., Metze, D., Kutzner, H., Kerl, H., Eds.; Springer: Berlin, Germany, 2016; Chapter 20; pp. $404-438$.

7. Metze, D. Disorders of Keratinization. In McKee's Pathology of the Skin, 5th ed.; 2-Volume-Set; Calonje, E., Brenn, T., Lazar, A., McKee, P.H., Eds.; Elsevier: Amsterdam, The Netherlands, 2019; Volume 1, Chapter 3, pp. 53-117.

8. Oji, V.; Metze, D.; Traupe, H. Inherited disorders of cornification. In Rook's Textbook of Dermatology, 9th ed.; Burns, T., Breathnach, S., Cox, N., Griffiths, C., Eds.; Wiley-Blackwell: Hoboken, NJ, USA, 2016; Volume 2, Part 6; Chapter 65, pp. 1-75.

9. Majmundar, V.D.; Baxi, K. Hereditary and Acquired Ichthyosis Vulgaris. In Treasure Island (FL); StatPearls Publishing: Treasure Island, FL, USA, 2021.

10. Süßmuth, K.; Gruber, R.; Rodriguez, E.; Traupe, H.; Amler, S.; Sánchez-Guijo, A.; Valentin, F.; Tarinski, T.; Straub, N.; Metze, D.; et al. Increased prevalence of filaggrin deficiency in 51 patients with recessive X-linked ichthyosis presenting for dermatologic examination. J. Investig. Dermatol. 2018, 138, 709-711. [CrossRef] [PubMed]

11. Kütting, B.; Traupe, H. Der erworbene Ichthyosis-ähnliche Hautzustand. Hautarztand 1995, 46, 836-840. [CrossRef]

12. Hotz, A.; Kopp, J.; Bourrat, E.; Oji, V.; Komlosi, K.; Giehl, K.; Bouadjar, B.; Bygum, A.; Tantcheva-Poor, I.; Hellström Pigg, M.; et al. Meta-Analysis of Mutations in ALOX12B or ALOXE3 Identified in a Large Cohort of 224 Patients. Genes 2021, 12, 80. [CrossRef]

13. Raghunath, M.; Hennies, H.C.; Velten, F.; Wiebe, V.; Steinert, P.M.; Reis, A.; Traupe, H. A novel in situ method for the detection of deficient transglutaminase activity in the skin. Arch. Dermatol. Res. 1998, 290, 621-627. [CrossRef]

14. Rothnagel, J.A.; Dominey, A.M.; Dempsey, L.D.; Longley, M.A.; Greenhalgh, D.A.; Gagne, T.A.; Huber, M.; Frenk, E.; Hohl, D.; Roop, D.R. Mutations in the rod domains of keratins 1 and 10 in epidermolytic hyperkeratosis. Science 1992, 257, 11281130. [CrossRef]

15. Rothnagel, J.A.; Traupe, H.; Wojcik, S.; Huber, M.; Hohl, D.; Pittelkow, M.R.; Saeki, H.; Ishibashi, Y.; Roop, D.R. Mutations in the rod domain of keratin 2e in patients with ichthyosis bullosa of Siemens. Nat. Genet. 1994, 7, 485-490. [CrossRef]

16. Traupe, H.; Kolde, G.; Hamm, H.; Happle, R. Ichthyosis bullosa of Siemens: A unique type of epidermolytic hyperkeratosis. J. Am. Acad. Dermatol. 1986, 14, 1000-1005. [CrossRef]

17. Avshalumova, L.; Fabrikant, J.; Koriakos, A. Overview of skin diseases linked to connexin gene mutations. Int. J. Dermatol. 2014, 53, 192-205. [CrossRef] [PubMed]

18. van Steensel, M.A.M.; Oranje, A.P.; van der Schroeff, J.G.; Wagner, A.; van Geel, M. The missense mutation G12D in connexin30.3 can cause both erythrokeratodermia variabilis of Mendes da Costa and progressive symmetric erythrokeratodermia of Gottron. Am. J. Med. Genet. A 2009, 149A, 657-661. [CrossRef]

19. van Geel, M.; van Steensel, M.A.; Küster, W.; Hennies, H.C.; Happle, R.; Steijlen, P.M.; König, A. HID and KID syndromes are associated with the same connexin 26 mutation. Br. J. Dermatol. 2002, 146, 938-942. [CrossRef]

20. Süßmuth, K.; Traupe, H.; Metze, D.; Oji, V. Ichthyoses in everyday practice: Management of a rare group of diseases. J. Dtsch. Dermatol. Ges. 2020, 18, 225-243. [CrossRef]

21. Chavanas, S.; Bodemer, C.; Rochat, A.; Hamel-Teillac, D.; Ali, M.; Irvine, A.D.; Bonafé, J.L.; Wilkinson, J.; Taïeb, A.; Barrandon, Y.; et al. Mutations in SPINK5, encoding a serine protease inhibitor, cause Netherton syndrome. Nat. Genet. 2000, 25, 141-142. [CrossRef] [PubMed]

22. Leclerc-Mercier, S.; Bodemer, C.; Furio, L.; Hadj-Rabia, S.; de Peufeilhoux, L.; Weibel, L.; Bursztejn, A.C.; Bourrat, E.; Ortonne, N.; Molina, T.J.; et al. Skin biopsy in Netherton Syndrome: A Histological review of a large series and new findings. Am. J. Dermatopathol. 2016, 38, 83-91. [CrossRef] [PubMed]

23. Oji, V.; Eckl, K.M.; Aufenvenne, K.; Nätebus, M.; Tarinski, T.; Ackermann, K.; Seller, N.; Metze, D.; Nürnberg, G.; Fölster-Holst, R.; et al. Loss of corneodesmosin leads to severe skin barrier defect, pruritus, and atopy: Unraveling the peeling skin disease. Am. J. Hum. Genet. 2010, 87, 274-281. [CrossRef] [PubMed]

24. Ramphul, K.; Kota, V.; Mejias, S.G. Child Syndrome. In Treasure Island (FL); StatPearls Publishing: Treasure Island, FL, USA, 2021.

25. Happle, R.; Koch, H.; Lenz, W. The CHILD syndrome. Congenital hemidysplasia with ichthyosiform erythroderma and limb defects. Eur. J. Pediatr. 1980, 134, 27-33. [CrossRef]

26. Bergqvist, C.; Abdallah, B.; Hasbani, D.J.; Abbas, O.; Kibbi, A.G.; Hamie, L.; Kurban, M.; Rubeiz, N. CHILD syndrome: A modified pathogenesis-targeted therapeutic approach. Am. J. Med. Genet. A 2018, 176, 733-738. [CrossRef]

27. König, A.; Happle, R.; Bornholdt, D.; Engel, H.; Grzeschik, K.H. Mutations in the NSDHL gene, encoding a 3beta-hydroxysteroid dehydrogenase, cause CHILD syndrome. Am. J. Med. Genet. 2000, 90, 339-346. [CrossRef] 
28. Samuelov, L.; Sarig, O.; Harmon, R.M.; Rapaport, D.; Ishida-Yamamoto, A.; Isakov, O.; Koetsier, J.L.; Gat, A.; Goldberg, I.; Bergman, R.; et al. Desmoglein 1 deficiency results in severe dermatitis, multiple allergies and metabolic wasting. Nat. Genet. 2013, 45, 1244-1248. [CrossRef]

29. McAleer, M.A.; Pohler, E.; Smith, F.J.D.; Wilson, N.J.; Cole, C.; MacGowan, S.; Koetsier, J.L.; Godsel, L.M.; Harmon, R.M.; Gruber, R.; et al. Severe dermatitis, multiple allergies, and metabolic wasting syndrome caused by a novel mutation in the N-terminal plakin domain of desmoplakin. J. Allergy. Clin. Immunol. 2015, 136, 1268-1276. [CrossRef]

30. Taiber, S.; Samuelov, L.; Mohamad, J.; Barak, E.C.; Sarig, O.; Shalev, S.A.; Lestringant, G.; Sprecher, E. SAM syndrome is characterized by extensive phenotypic heterogeneity. Exp. Dermatol. 2018, 27, 787-790. [CrossRef] [PubMed]

31. Polivka, L.; Hadj-Rabia, S.; Bal, E.; Leclerc-Mercier, S.; Madrange, M.; Hamel, Y.; Bonnet, D.; Mallet, S.; Lepidi, H.; Ovaert, C.; et al. Epithelial barrier dysfunction in desmoglein-1 deficiency. J. Allergy Clin. Immunol. 2018, 142, 702-706.e7. [CrossRef]

32. Hammers, C.M.; Stanley, J.R. Desmoglein-1, differentiation, and disease. J. Clin. Investig. 2013, 123, 1419-1422. [CrossRef] [PubMed]

33. Ishida-Yamamoto, A.; Igawa, S. Genetic skin diseases related to desmosomes and corneodesmosomes. J. Dermatol. Sci. 2014, 74, 99-105. [CrossRef] [PubMed]

34. Metze, D.; Oji, V. Palmoplantar Keratodermas. In Dermatology, Series: Expert Consult, 4th ed.; Bolognia, J., Schaffer, J., Cerroni, L., Eds.; Elsevier: Philadelphia, PA, USA, 2018; Volume 1, Chapter 58, pp. 924-943. 